36. Косорукова Н.В., Кулькова М.А., Пиецонка Х., Нестерова Л.А., Семенцов А.А., Лебедева Л.М., Тербергер Т., Харц С. Радиоуглеродное датирование неолитических памятников в местности Караваиха в бассейне озера Воже // Радиоуглеродная хронология эпохи неолита Восточной Европы VII-III тыс. до н.э.: колл. моногр. / сост. Г.И. Зайцева, О.В. Лозовская, А.А. Выборнов, А.Н. Мазуркевич. Смоленск: Свиток, 2016. С. 410-424.

37. Кулькова М.А., Косорукова Н.В., Сапелко Т.В. Палеогеографические условия жизнедеятельности древнего человека в раннем неолите в бассейне озера Воже // Неолитические культуры Восточной Европы: хронология, палеоэкология, традиции: материалы междунар. науч. конф., посв. 75-летию В.П. Тре- тьякова / под ред. В.М. Лозовсого, О.В. Лозовской, А.А. Выборнова. СПб.: ИИМК РАН, 2015. С. 281-284.

38. Калинина И.В., Гаджиева (Устинова) Е.А. Архаические орнаментиры для керамики // Археологические изыскания. Вып. 10. СПб., 1993. С. 83-94.

39. Гурина Н.Н. Древняя история северо-запада Европейской части СССР // Материалы и исследования по археологии СССР. № 87. М., Л.: Наука, 1961. $248 \mathrm{c}$.

40. Ivanischeva M., Kanin M., Ivanischeva A. The South-East Onega Region`s ceramic traditions in the Early Neolithic // European Assjciation of Archaeologists. 18 th annual meeting 29 august -1 September 2012, Helsinki, Finland. Abstracts. P. 232.

\title{
ORIGINS OF THE POTTERY TRADITIONS IN THE EARLY NEOLITHIC EUROPEAN NORTH OF RUSSIA
}

(C) 2018

Ivanischeva Marina Viktorovna, head

Eastern-Prionezhye Archaeological Expedition (Vologda, Russian Federation)

Abstract. The following paper deals with origins of the pottery traditions in the early Neolithic European North of Russia. At present there is a prevailing scheme of ornamental styles development stages in the Early Neolithic antiquities forest zone of the European part of Russia - from pinned-point/without ornament to the later ornamental comb tradition. Among the series of dates taken as a chronological frame for the Neolithic forest belt around 7000 years ago, there are deeper/ancient definitions for pricked fragments, as well as vessels with comb-style ornamentation. The paper presents technical and technological analysis of the ceramic complex of monuments in Berezovaya Slobodka in Nyuksensky district and monuments in Tudozere and Kemozere in Vytegra district.

Keywords: Early Neolithic; ceramics; typology; technology; absolute dating; analogies; borrowing vectors; South-Eastern Prionezhye; Vytegorsky district; Tudozero-V settlement; Kemskoe III settlement; Lower Sukhona; Berezovaya Slobodka II-III settlement; Berezovaya Slobodka VI settlement; Vologda Region.

УДК $903.024(470.22 / 23)$

Статья поступила в редакцию 02.06.2018

\section{КУЛЬТУРА СПЕРРИНГС (СОВРЕМЕННОЕ СОСТОЯНИЕ ИЗУЧЕНИЯ)}

(C) 2018

Герман Константин Энрикович, кандидат исторических наук, старший научный сотрудник сектора археологии

Институт языка, литературы и истории Карельского научного иентра РАН (2. Петрозаводск, Российская Федерация)

\begin{abstract}
Аннотащия. С момента последних обобщающих публикаций по раннему неолиту Карелии прошло более десятка лет. За этот период были открыты и изучены новые памятники культуры сперрингс, получены первые AMS-датировки по нагару с фрагментов керамики, изучались памятники раннего неолита на сопредельных территориях. В результате проведенных за два десятилетия археологических исследований на территории Карелии было открыто и исследовано более десятка новых памятников, в том числе на мало исследованных территориях Северного Приладожья и Карельского перешейка. Центром культуры сперрингс является бассейн Онежского озера, где известно более 200 поселений. Время существования культуры сперрингс в бассейне Онежского озера на основании AMS-датировок 5306-4250 calBC. Также с этими данными согласуются AMS-датировки по кальцинированным костям с поселения Койриноя III в Северном Приладожье. Появление керамики сперрингс на территории Карелии происходит практически одновременно, однако если в бассейне Онежского озера ранними являются сосуды с позвонковой орнаментацией, то в северо-западном Приладожье и Карельском перешейке - посуда, украшенная отступающими и прочерченными линиями. Возможно, это связано с тем, что на Онежское озеро керамику сперрингс приносит пришлое население, а на Ладожском озере и Карельском перешейке глиняная посуда появляется в среде местного мезолитического населения в результате заимствования.

Ключевые слова: Карелия; Онежское озеро; Ладожское озеро; северо-западное Приладожье; Карельский перешеек; культура сперрингс; хронология; AMS-датировки; ранний неолит; керамика сперрингс; гребенчатая керамика; поселение Тудозеро V; поселение Кемозеро III; происхождение археологической культуры.
\end{abstract}

На территории Карелии и сопредельных с ней Ленинградской и Вологодской областей в раннем неолите известны археологические памятники, которые по составу и формам каменного инвентаря и орнаментации глиняной посуды были выделены в археологическую культуру сперрингс. Основной зоной их распространения были берега Онежского озера, а также рек и озер, относящихся к его бассейну. Не- 
Герман К.Э.

большое количество памятников известно в бассейне Ладожского озера и Прибеломорье.

С момента последних обобщающих публикаций по раннему неолиту Карелии прошло более десятка лет. За этот период были открыты и изучены новые памятники культуры сперрингс, получены первые AMS-датировки по нагару с фрагментов керамики, изучались памятники раннего неолита на сопредельных территориях. Все это позволяет на современном этапе изучения уточнить границы распространения культуры сперрингс, уточнить хронологические рамки ее существования и по-новому взглянуть на вопрос ее происхождения.

\section{История изучения культуры сперрингс}

в 2000-x годах

Археологические исследования культуры сперрингс разделяются на археологические обследования территорий, в ходе которых открывались поселения с керамикой сперрингс и целенаправленные исследования уже известных комплексов. Основными районами, где проводились данные работы, был Карельский перешеек, северное Приладожье и побережье Онежского озера (рис. 1).

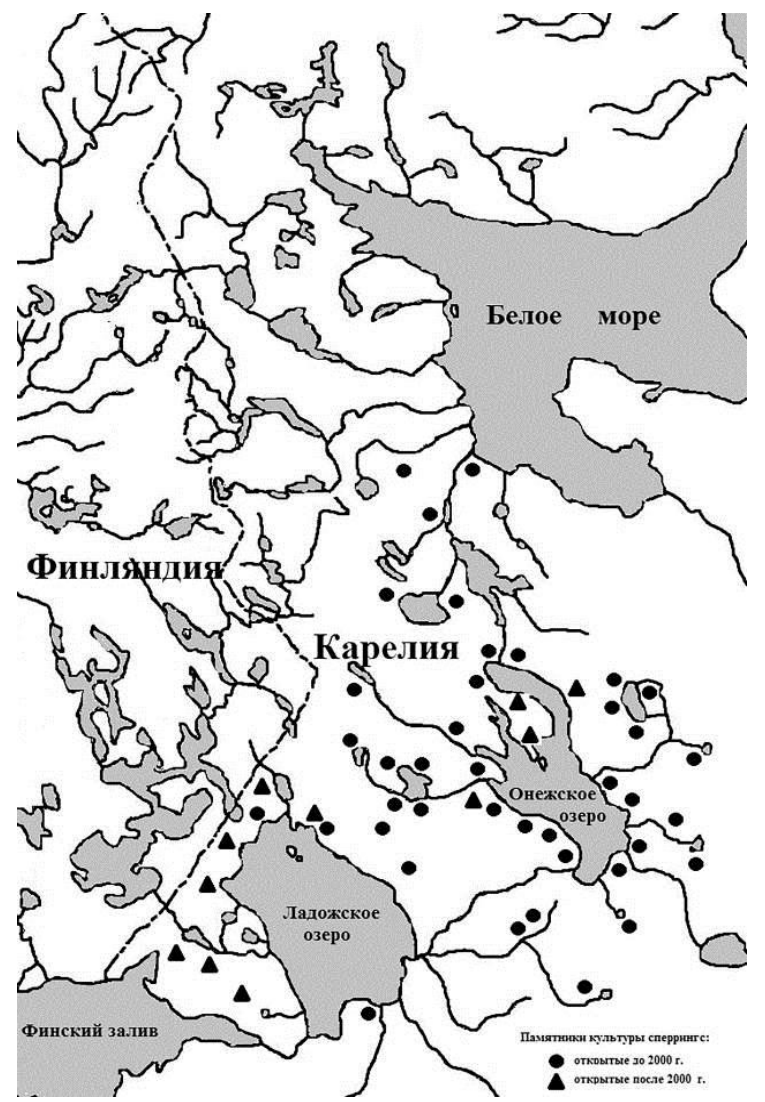

Рисунок 1 - Памятники культуры сперрингс на территории Карелии

На Карельском перешейке в ходе археологических работ, проводимых В.И. Тимофеевым и Д.В. Герасимовым, было открыто и исследовано четыре памятника с ранненеолитическими слоями: Силино, Комсомольское, Вещево 1 и Куркиёки 33 [1]. Важность проведенных археологических и палеогеографических исследований заключалась в том, что на основании междисциплинарного подхода в изучении древностей каменного века территории Карельского перешейка и Финского залива исследователям удалось сделать выводы о закономерностях расположения поселений мезолита - энеолита. В северном
Приладожье М.М. Шахновичем и И.Ф. Витенковой были открыты и исследовались раскопками поселения раннего неолита Вятиккя I, Ихоярви I Вяртсиля VI и Койриноя III, давшие новую информацию о заселении этой территории $[2$, с. $43-68$, с. $82-101 ; 3$, c. $169-172 ; 4$, с. 11].

В Ленинградской области на юго-западном побережье Онежского озера в 2007-2008 гг. Т.М. Гусенцовой на площади $86 \mathrm{~m}^{2}$ было исследовано поселение культуры сперрингс Щелейки. Этот памятник располагается между поселениями с керамикой сперрингс в районе с. Шелтозера и п. Уя карельского берега и поселением Тудозеро V около г. Вытегра и может быть звеном в решении вопроса появления первой керамической посуды в бассейне Онежского озера [5].

На территории Карелии по берегам Онежского озера К.Э. Германом были открыты ранненеолитические поселения, которые входят в состав комплексов памятников мезолита - энеолита на восточном берегу Онежского озера в районе с. Пяльма, по берегам озера Лижмозеро, в среднем течении реки Суна на территории заповедника «Кивач», по берегам озер Ванчозеро и Комозеро на территории Заонежского полуострова [6, с. 274-292; 7, с. 53-64]. Им же были исследованы раскопки поселения культуры сперрингс на территории Южного Заонежья и низовьев реки Шуя [8; 9]. Два поселения раннего неолита Пески 8 и Больничный 1 раскопал А.М. Жульников.

Также в последние годы удалось получить ряд AMS-датировок нагара с фрагментов керамики сперрингс нескольких ранненеолитических памятников (Панозеро 1, Уя III, Оровнаволок V, Сулгу II, Вожмариха 26, Шелтозеро V), что позволило уточнить время функционирования отдельных археологических комплексов и сравнить их с радиоуглеродными определениями, полученными из культурных слоев [10, c. 39-43].

\section{Территория распространения памятников с керамикой сперрингс}

Проведенные в последние два десятилетия археологические исследования подтвердили, что центром культуры сперрингс является бассейн Онежского озера. В настоящее время здесь известно более 200 поселений, среди которых выделяются четыре вида:

- стоянки, функционирующие в определенный сезон времени, имеющие небольшую площадь 100$200 \mathrm{M}^{2}$;

- стоянки, функционирующие большую часть года, с жилой площадкой площадью 250-600 м², выраженной в рельефе; культурный слой окрашен в малиново-красный цвет; имеются остатки хозяйственных сооружений: ямы, кострища и очаги;

- стоянки, функционирующие круглый год, площадью 1000-3000 м², или места многократного использования, имеющие жилую площадь свыше 1000 м²; культурный слой окрашен в малиново-красный цвет; имеются остатки хозяйственных сооружений: каменные кладки, ямы, кострища и очаги;

- поселения площадью свыше $1000 \mathrm{~m}^{2}$ с остатками наземных жилищ [11, с. 574].

По берегам Ладожского озера и на Карельском перешейке в настоящее время известно только 27 поселений с керамикой сперрингс, что может объясняться рядом причин:

1) недостаточная изученность в археологическом плане; 
2) сложные геологические процессы в образовании котловины Ладожского озера, в результате которых часть памятников раннего неолита оказалась размытой (стоянка Березье) или перекрытой озерными отложениями (стоянка Усть-Рыбежна 1), а также удаленной на большое расстояние от современной береговой линии, что затрудняет их поиски;

3) «транзитный» характер Ладожского озера, при котором древнее население по пути р. Нева - Ладожское озеро - р. Свирь переправлялось в Онежское озеро.

\section{Хронологические рамки существования}

культуры сперрингс

В настоящее время хронологические рамки существования культуры сперрингс определяются серединой V - серединой IV тыс. до н.э. (по некалибровочным данным). К.Э. Германом в ходе разработки периодизации данной ранненеолитической культуры были привлечены радиоуглеродные определения, данные высотного расположения поселений и геоморфологических исследований, сравнительно-типологический анализ керамики и каменного инвентаря [12]. В соответствии с периодизационной схемой самой древней является керамика, украшенная оттисками рыбьих позвонков и подокруглыми ямками (рис. 2), а к позднему этапу относится глиняная посуда, орнаментированная отступающе-прочерченными линиями и подромбическими ямочными вдавлениями (рис. 3).

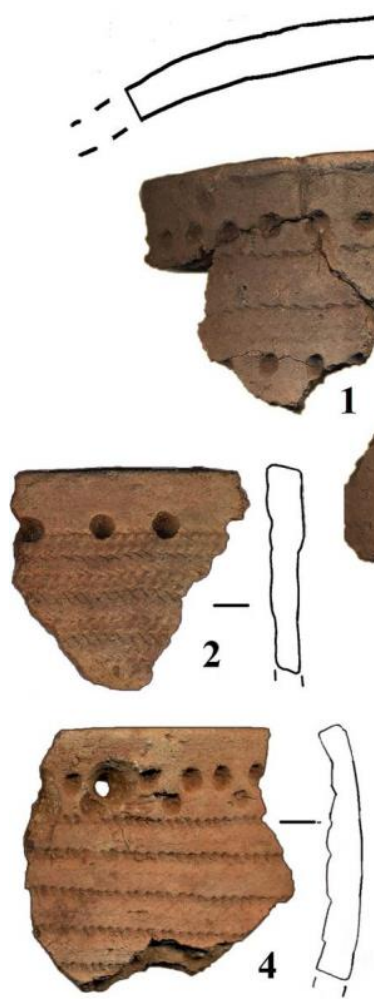

Рисунок 2 - Керамика сперрингс с позвонковым орнаментом.

1, 3, 5- Пиндуши III; 2, 4- Пегрема II

Вопрос происхождения

культуры сперрингс

В последних работах, посвященных каменному веку Карелии, версия преемственности культуры сперрингс к местной мезолитической культуре бассейна Онежского озера была убедительно опровергнута $[13$, с. $120 ; 14$, с. 119-120]. По мнению исследо-
Применение нового метода AMS-датировки по нагару с поверхности керамических сосудов, а также кальцинированных костей позволило получить первые результаты, уточняющие время существования культуры сперрингс в бассейне Онежского и Ладожского озер. Всего было выполнено 15 AMS-датировок, в том числе шесть с фрагментов керамики с позвонковым орнаментом с памятников Сулгу II, Уя III, Тудозеро V, относимых исследователями к раннему этапу существования культуры сперрингс (табл. 1).

В результате эти датировки оказались в диапазоне 5306-4729 calBC, что, таким образом, маркирует начало существования памятников культуры сперрингс в бассейне Онежского озера. Также с этими данными согласуются AMS-датировки по кальцинированным костям с поселения Койриноя III в Северном Приладожье [4, с. 171]. Эти данные значительно «омолаживают» начало раннего неолита в Карелии и не согласуются с ранее полученными по углю радиоуглеродными определениями, которые датируют появление первой керамики в диапазоне 5750-5650 calBC, что на 300-400 лет древнее.

Финальный этап культуры сперрингс в бассейне Онежского озера маркирует одна AMS-датировка с поселения Вожмариха 26, которая находится в диапазоне 4460-4250 calBC, что соответствует хронологической схеме раннего неолита Карелии.
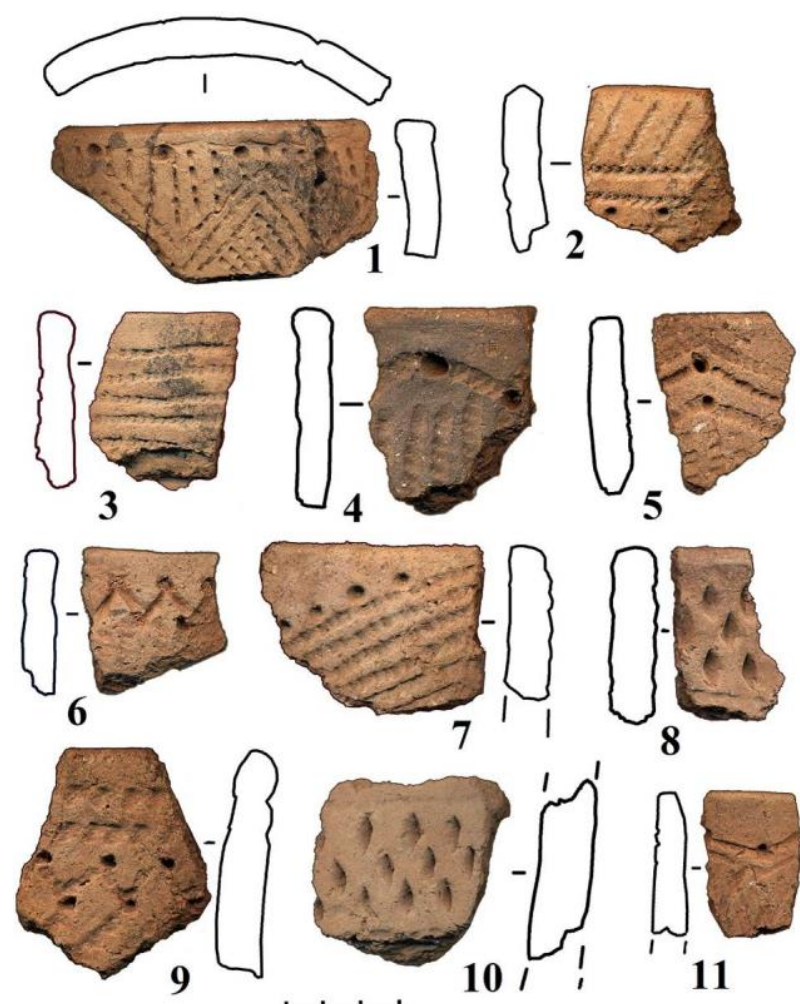

Рисунок 3 - Керамика сперрингс

с отступающе-прочерченным орнаментом. 1-3, 8, 10- Деревянное Іа; 4-7, 9, 11 - Кочнаволок I вателей, об этом свидетельствует сокращение площадей стоянок, снижение численности финальномезолитических коллективов и отличная от ранненеолитической техника обработки камня. Поэтому возникает вопрос о месте появления и путях проникновения нового населения с керамикой сперрингс в бассейн Онежского озера. 
Герман К.Э.

Культура сперрингс (современное состояние изучения)

07.00.00 - исторические науки и археология

Таблица 1 - Радиоуглеродные определения с памятников культуры сперрингс

\begin{tabular}{|c|c|}
\hline Даты по углю & AMS-даты (нагар, кость) \\
\hline \multicolumn{2}{|c|}{ Бассейн Онежского озера } \\
\hline $\begin{array}{l}\text { Вожмариха } 26 \\
6100-5350 \text { calBC }(6800 \pm 200 \text { BP })(\text { (ЛЕ-6190) } \\
5650-5370 \text { calBC }(6580 \pm 80 \text { BP })(\text { ЛE-3422) }\end{array}$ & $4460-4250$ calBC $(5507 \pm 50 \mathrm{BP})(\mathrm{KIA}-35901)$ \\
\hline $\begin{array}{c}\text { Оровнаволок V } \\
4910-4500 \text { calBC (5850 } \pm 80 \text { ВР) (TA-2265) } \\
4720-4440 \text { calBC }(5720 \pm 60 \text { BP) (TA-2266) } \\
\end{array}$ & $4932-4725$ calBC $(5945 \pm 40 \mathrm{BP})(\mathrm{GrA}-63735)$ \\
\hline Панозеро I & 4730-4540 calBC (5795 \pm 35 BP) (KIA-33924) \\
\hline \multicolumn{2}{|l|}{$\begin{array}{c}\text { Пегрема IX } \\
5750-5050 \text { calBC (6510 } \pm 80 \text { BP) (TA-1161) } \\
\end{array}$} \\
\hline Силино & 4800-4440 calBC (5830 \pm 80 BP) (Hela-554) \\
\hline Сулгу II & $\begin{array}{l}5660-5520 \text { calBC }(6670 \pm 35 \text { ВР) }(\mathrm{KIA}-35900) \\
5210-4900 \text { calBC }(6085 \pm 30 \text { л.н.) (KIA-36724) } \\
5000-4830 \text { calBC }(6015 \pm 30 \text { л.н.) (KIA-33925) }\end{array}$ \\
\hline $\begin{array}{l}\text { Тудозеро V } \\
5321-5058 \text { calBC (6250 } \pm 50 \text { ВР) (ГИН-8050) } \\
5470-4860 \text { calВС (6230 } \pm 120 \text { ВР) (ГИН-7663) } \\
5298-4801 \text { calBC }(6110 \pm 100 \text { ВР) (ГИН-7662) } \\
5048-4936 \text { calBC }(6075 \pm 20 \text { ВР) (ЛЕ-6699) }\end{array}$ & $5306-5076$ calBC $(6241 \pm 30 \mathrm{BP})(\mathrm{AAR}-17173)$ \\
\hline Уя III & $\begin{array}{l}5304-5059 \text { calBC }(6225 \pm 40 \mathrm{BP})(\mathrm{GrA}-63566) \\
5217-5000 \text { calBC }(6160 \pm 40 \mathrm{BP})(\mathrm{GrA}-63581) \\
4956-4729 \text { calBC }(5970 \pm 40 \mathrm{BP})(\mathrm{GrA}-63546)\end{array}$ \\
\hline \multicolumn{2}{|l|}{$\begin{array}{c}\text { Шелтозеро X } \\
5510-5210 \text { calBC }(6400 \pm 80 \text { BP) (ТА-1308) }\end{array}$} \\
\hline Шелтозеро V & 4839-4617 calBC (5870 \pm 40 BP) (GrA-63587) \\
\hline \multicolumn{2}{|l|}{ 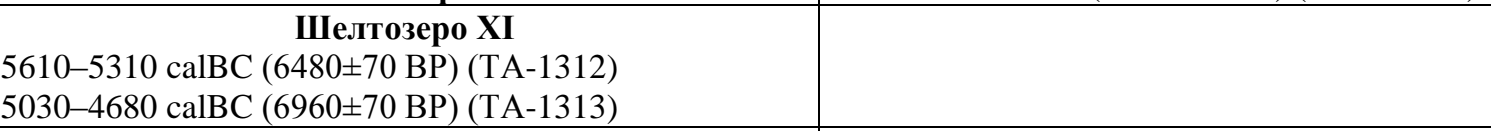 } \\
\hline \multicolumn{2}{|l|}{$\begin{array}{c}\text { Шеттима I } \\
5650-5000 \text { calBC }(6400 \pm 150 \text { BP) (TA-1152) }\end{array}$} \\
\hline \multicolumn{2}{|c|}{ Бассейн Ладожского озера } \\
\hline \multicolumn{2}{|l|}{$\begin{array}{c}\text { Вещево 1 } \\
4800-4400 \text { calBC (5770 } \pm 130 \text { ВР) (ЛЕ-6511) }\end{array}$} \\
\hline Койриноя 3 & $\begin{array}{l}5325-5075 \text { calBC }(6262+-40 \text { BP })(\text { Hela-2827) } \\
5305-5050 \text { calBC }(6209+-43 \text { BP) (Hela-2829) } \\
\end{array}$ \\
\hline Комсомольское 3 & $4530-4370$ calBC $(5635 \pm 45 \mathrm{BP})($ Hela-1817) \\
\hline $\begin{array}{c}\text { Куркиёки 33 } \\
6000-4700 \text { calBC (6400 } \pm 600 \text { ВР) (ЛЕ-6928) }\end{array}$ & \\
\hline $\begin{array}{r}\text { Хепоярви } \\
5440-5352 \text { calBC }(6480 \pm 80 \mathrm{BP}) \\
5424-5264 \text { calBC }(6380 \pm 60 \mathrm{BP}) \\
\end{array}$ & \\
\hline
\end{tabular}

Большинство исследователей связывает появление первой керамики в Карелии с глиняной посудой второго этапа верхневолжской культуры, который хронологически соответствует раннему этапу культуры сперрингс [15, с. 76; 16, с. 40; 17, с. 69]. Однако наряду со сходством в орнаментации и форме сосудов между ними существуют и большие различия, например полное отсутствие оттисков рыбьих позвонков в верхневолжской керамике и небольшое количество веревочных и гребенчатых оттисков в сперрингс.

По мнению автора, ближайшим аналогом является керамика поселения Тудозеро V, которое находится в районе г. Вытегра на южном побережье Онежского озера. На памятнике, который исследовался А.М. Иванищевым и М.В. Иванищевой, в ходе раскопок было выделено два комплекса с ранненеоли- тической керамикой. В нижнем слое стратиграфически определяется посуда с гребенчатой орнаментацией, а в верхнем - керамика с позвонковым орнаментом. С нижнего слоя по нагару керамическая посуда с гребенчатым орнаментом датируется по AMS 5636-5530 calBC $(6660 \pm 32)$ (AAR-17174). С верхнего горизонта посуда с позвонковой орнаментацией имеет AMS-датировку 5306-5076 calBC (6241 \pm 30 BP) (AAR-17173). По мнению М.В. Иванищевой, paдиоуглеродные определения маркируют время появления двух групп ранненеолитического населения на поселении Тудозеро V [18, с. 401].

На основании петрографического анализа ранненеолитической керамики поселения Тудозеро V, проведенного М.А. Кульковой, было выделено две технологические традиции составления формовочных масс. Первая, с дресвой и/или песком, характеризует 
керамику с позвонковой орнаментацией, вторая, с дресвой, песком, шамотом и органикой - с гребенчатой, что позволило А.М. Иванищевой предположить формирование керамики близкой сперрингс на основе гребенчатых комплексов. В то же время посуда с гребенчатой орнаментацией имеет отдаленные аналогии в керамических комплексах лесной полосы зауральского региона [19].

Однако надо отметить большой хронологический разрыв между гребенчатой керамикой и сперрингс, а также отсутствие «гибридных» форм в формах сосудов и их орнаментации. В качестве переходного этапа между двумя типами ранненеолитической посуды A.M. Иванищева указывает керамику поселения Кемское III, где гребенчатая керамика представлена семью сосудами, а керамика сперрингс 34 сосудами с позвонковым, прочерченным и отступающим орнаментом, относящимися к развитому этапу культуры сперрингс. Радиоуглеродных определений с памятника не получено, в керамическом комплексе присутствует также керамика, орнаментированная ямчатыми наколами, что, на взгляд автора, свидетельствует о смешанном характере материалов и не позволяет делать вывод о его возрасте [20, с. 298, 299].

Таким образом, убедительных доказательств преемственности керамики сперрингс к гребенчатой посуде южного Обонежья на сегодняшний день нет. Важно отметить, что сам процесс неолитизации бассейна Онежского озера происходил синхронно, на что указывают радиоуглеродные определения с поселений побережья Онеги и соединенных с ним крупных озер Сямозера и Водлозера. Ранний этап представлен памятниками с керамикой, украшенной оттисками рыбьего позвонка, позднее появляется и увеличивается количество сосудов с отступающепрочерченной орнаментацией, что также подтверждается радиоуглеродными датировками.

Несколько иная ситуация складывается на территории Карельского перешейка. Здесь ранние радиоуглеродные определения получены с памятников, в комплексах которых преобладает керамика сперрингс с отступающе-прочерченной орнаментацией (например, Хепоярви) [21, с. 146, 147]. Аналогичная ситуация в раннем неолите Финляндии, где большая часть керамической посуды орнаментирована отступающими и прочерченными линиями [16, с. 41]. В этой связи можно привести точку зрения, высказанную Д.В. Герасимовым, что формирование ядра культуры сперрингс происходило в районе Карельского перешейка на основе местной мезолитической культурной традиции и культурного влияния в виде гончарных традиций с территории Верхней Волги. Исследователь приходит к выводу о том, что комплексы раннего неолита Карельского перешейка по составу каменного инвентаря и отходов производства, соотношению биполярной и площадочной техники изготовления орудий из кварца по сырьевому составу имеют много общих черт с индустрией позднего мезолита. Д.В. Герасимовым было отмечено малое количество готовых форм орудий, преобладание орудий из местного сырья, а также полное господство отщепной техники получения заготовок. Орудий на пластинах и микропластинах нет [1, с. 20].

\section{Выводы}

В результате проведенных за два десятилетия археологических исследований памятников раннего неолита на территории Карелии было открыто и исследовано более десятка новых памятников, в том числе на слабо исследованных территориях Северного Приладожья и Карельского перешейка. Центром культуры сперрингс является бассейн Онежского озера, где известно более 200 поселений. Появление керамики сперрингс на территории Карелии происходит практически одновременно, однако если в бассейне Онежского озера ранними являются сосуды с позвонковой орнаментацией, то в северо-западном Приладожье и Карельском перешейке - посуда, украшенная отступающими и прочерченными линиями. Вполне вероятно, это связано с тем, что на Онежское озеро керамику сперрингс приносит пришлое население, а на Ладожском озере и Карельском перешейке глиняная посуда появляется в среде местного мезолитического населения в результате заимствования.

\section{Список литературы:}

1. Герасимов Д.В. Динамика каменных индустрий мезолита - неолита Карельского перешейка: автореф. дис. ... канд. ист. наук. СПб., 2012. 29 с.

2. Витенкова И.Ф. Памятники каменного века Северного Приладожья. Каталог. Петрозаводск: Изд-во КарНЦ РАН, 2012. 156 с.

3. Шахнович М.М., Тарасов А.Ю., Такала Х. Новые памятники каменного века в Северном Приладожье // Проблемы изучения эпохи первобытности и раннего Средневековья лесной зоны Восточной Европы. Выпуск IV. Иваново: Издатель Ольга Епишева, 2015. C. 165-176.

4. Шахнович М.М., К Кожевникова Ю.Н., Бельский С.В., Гермасимов Д.В., Лисицын С.Н., Хартанович В.И., Форсберг О., Карьялайнен Т., Майонен Е., Песонен П. Российско-финляндские археологические изыскания в Северном и Западном Приладожье: взгляд из России и Финляндии. Петрозаводск, 2007. C. $10-15$.

5. Гусенцова Т.М. Исследования памятников неолита на южном побережье Онежского озера (Ленинградская область) // Тверской археологический сборник. 2013. Вып. 9. С. 222-231.

6. Герман К.Э. Работы археологической экспедиции музея-заповедника «Кижи» в Пудожском районе Республики Карелия // Изучение и актуализация традиционной культуры. Петрозаводск: Изд-во КНЦ РАН, 2016. С. 274-292.

7. Герман К.Э. Древние поселения на озере Лижмозеро // Археология Севера. Вып. 5. Череповец: Изд-во «Принт Ателье», 2014. С. 53-64.

8. Герман К.Э. Поселения с керамикой сперрингс Южного Заонежья // Русская культура нового столетия: проблемы изучения, сохранения и использования историко-культурного наследия: сборник материалов всерос. конф. Вологда: Изд-во «Элекон». 2007. C. 55-60.

9. Герман К.Э. Раскопки поселения Гарнизон Бесовец в Прионежском районе Карелии // Кижский вестник. № 11. Петрозаводск: Изд-во КНЦ РАН. 2007. C. 190-205.

10. Нордквист К., Мекканен Т. Новые данные по археологической хронологии Северо-Запада России: AMS-датировки неолита - энеолита Карелии // Тверской археологический сборник. 2018. Т. 11. С. 39-68.

11. Герман К.Э. Культура сперрингс на территории Карелии // Первобытные древности Евразии: к 
Герман К.Э.

60-летию Алексея Николаевича Сорокина. М.: Издво ИА РАН. 2012. С. 571-590.

12. Герман К.Э. Хронология и периодизация культуры сперрингс // Тверской археологический сборник. 2002. Вып. 5. С. 264-273.

13. Филатова В.Ф. Мезолит бассейна Онежского озера. Петрозаводск: Изд-во КарНЦ РАН, 2004. $274 \mathrm{c}$.

14. Тарасов А.Ю. Адаптация к локальной сырьевой базе, технологическое развитие каменных индустрий и социальное развитие древних обществ: на примере культур Карелии периода неолита - раннего железного века // Адаптация культуры населения Карелии к особенностям местной природной среды периода мезолита - Средневековья. Петрозаводск: Издво КарНЦ РАН, 2009. Вып. 4. С. 111-134.

15. Витенкова И.Ф. Культура сперрингс // Археология Карелии. Петрозаводск: Изд-во КарНЦ РАН, 1996. С. 65-81.

16. Панкрушев Г.А. Мезолит и неолит Карелии. Л.: Наука, 1978. Ч. II. 164 с.

17. Песонен П.Э. Хронология и периодизация культуры сперрингс // Хронология и периодизация археологических памятников Карелии. Петрозаводск: Изд-во КарНЦ РАН, 1991. С. 65-85.

18. Иванищева М.В., Кулькова М.А., Иванищева Е.А. Радиоуглеродная хронология раннего неолита Нижней Сухоны и Юго-Восточного Прионежья // Радиоуглеродная хронология эпохи неолита Восточной Европы VII-III тыс. до н.э. Смоленск: Изд-во «Свиток». 2016. С. 397-409.

19. Иванищева М.В. К вопросу о времени и истоках гончарных традиций в раннем неолите Европейского Севера России // Неолитизация Северной Евразии: теории, гипотезы, факты: I междунар. интернетконф. 1 июля 2016 г. - 31 января 2017 г. Омск, 2017.

20. Иванищев А.М., Иванищева М.В. Поселение раннего неолита на Кемском озере // Тверской археологический сборник. Вып. 4. 2000. С. 297-305.

21. Верещагина И.В. Поселение Хепоярви в южной части Карельского перешейка // Неолит энеолит юга и неолит севера Восточной Европы. СПб.: Изд-во ИИМК РАН, 2003. С. 140-151.

Работа выполнена из средств федерального бюджета на выполнение государственного задания КарНЦ РАН.

\title{
THE SPERRINGS CULTURE (CURRENT STATE OF STUDY)
}

(C) 2018

German Konstantin Enrikovich, candidate of historical sciences, senior researcher of Archaeology Sector Institute of Linguistics, Literature and History of Karelian Research Centre of Russian Academy of Sciences (Petrozavodsk, Russian Federation)

Abstract. The following paper deals with the study of the Sperrings culture. More than a decade has passed since the last general publications on early Neolithic of Karelia. During this period, new sites of the Sperrings culture have been discovered and studied, first AMS-dating has been received from the ceramic fragments, monuments of the early Neolithic in the neighboring territories have been studied. As a result of two decades of the archaeological research in Karelia more than a dozen of new monuments were discovered and investigated, including poorly explored areas of the Northern Ladoga and Karelian isthmus. The Sperrings culture centre is the Onega lake basin, where more than 200 settlements are known. The existence period of the Sperrings culture in the Onega lake basin on the basis of AMS-dates is 5306-4250 cal BC. These data are also consistent with AMS-dating of bones of Koirinoya III settlement in the North Ladoga area. The Sperrings ceramics appeared on the territory of Karelia at the same time.

Keywords: Karelia lake Onega; lake Ladoga; North-Western Ladoga Region; Karelian Isthmus; Sperrings culture; chronology; AMS-Dating; early Neolithic; Sperrings ceramics; comb ceramics; Tudozero V settlement; Kemozero III settlement; origins of archaeological culture.

УДК 902.2, 903.2, 903-4

Статья поступила в редакцию 09.06.2018

\section{КЕРАМИЧЕСКАЯ ПОСУДА В КУЛЬТУРЕ БРОДЯЧИХ ОХОТНИКОВ КРАЙНЕГО СЕВЕРО-ВОСТОКА ЕВРОПЫ}

(C) 2018

Карманов Виктор Николаевич, кандидат исторических наук, заведующий сектором сохранения и популяризации археологического наследия Институт языка, литературы и истории Коми научного иентра УрО РАН

\author{
(2. Сыктывкар, Российская Федераџия)
}

\begin{abstract}
Аннотация. В статье обобщены и систематизированы первичные данные о керамической посуде неолита и энеолита Крайнего северо-востока Европы. Автор проанализировал сведения об археологических контекстах керамической посуды, ее количественные (число емкостей в каждом комплексе) и качественные (форму, пропорциональность и объем сосудов) характеристики. Для оценки познавательной возможности доступных источников использован критический анализ. В результате прослежены динамика количественных и качественных параметров керамической посуды в течение VI - первой половины II тыс. до н.э. и их различия в связи с различной культурной принадлежностью. Установлено, что в первой половине V тыс. до н.э. керамика в виде наборов посуды разных объемов и видов становится неотъемлемой частью повседневности бродячих охотников региона. В связи с их образом жизни потребность в керамике была ограниченна: среднее число одновременно использованных сосудов в среднем 3-4 емкости на контекст. При этом преобладают простейшие формы - круглодонные горшки объемами до 25 л и мискообразная посуда до 2,5 л.
\end{abstract}

